\title{
Resultados de la Utilización de Google Docs en Procesos de Mentorización con Alumnado de Tercer Ciclo ${ }^{1}$.
}

Cinta C. García Vázquez* Ignacio Tejera Arcenillas***

\section{RESUMEN:}

Este artículo aporta la experiencia desarrollada en el Observatorio Local de Empleo de la Universidad de Huelva durante la estancia de investigación del alumnado del Máster en Politicas Territoriales de Empleo, en la que se ha utilizado Google Docs como herramienta de trabajo y de comunicación, lo que ha permitido al alumnado aprender y desarrollar el proceso de investigación de forma colaborativa. Se ha constatado que Google Docs es un sistema de trabajo que permite crear conocimiento colectivo, lo cual le confiere un papel relevante como medio para gestionar grupos de trabajo en el ámbito educativo.

\section{Abstract:}

This article provides the experience developed in the Local Employment Observatory of the University of Huelva during the research stay of the students of Master in Territorial Employment Policy, where we has used Google Docs as a working tool and communication, which has allowed students to learn and develop the research process collaboratively. It was found that Google Docs is a system that lets you create collective knowledge, which gives it a role as a means to manage working groups in education.

* Departamento de Economía. U. de Huelva • cinta.garcia@decd.uhu.es

** Departamento de Economía. U. de Huelva • ignacio.tejera@dege.uhu.es

1. Los dos autores tienen la misma importancia en el artículo. 
PALABRAS Claves:

Google Docs, Conocimiento colaborativo, Investigación en red, Mentoring.

KEYWORDS:

Google Docs, Collaborative Knowledge, Research Network, Mentoring

\section{1.- INTRODUCCIÓN}

En España los estudios de relaciones laborales han experimentado una serie de mejoras, desde sus modelos originales, tanto en su articulación como en sus contenidos. Tal como indica el profesor A. Galán (2005) de las primitivas Escuela dependientes del Ministerio de Trabajo, con una marcada función de instrucción popular, se llegó a centros plenamente integrados en el sistema de enseñanza superior, con un carácter plenamente universitario.

Haciendo un pequeño recorrido histórico, en octubre de $1919^{2}$, se aprueban lo que serían los estudios de Graduado Social. Sin embargo, no será hasta el año $1925^{3}$ cuando comiencen lo que hoy conocemos como estudios de relaciones laborales, creándose la primera Escuela Social4. La enseñanza dentro de las citadas escuelas, estaba organizada en estudios regulares con una duración de tres años, orientadas principalmente a materias de política social, economía y legislación. Y las acciones formativas incluían conferencias divulgativas, cursillos y excursiones para todos aquellos que quisieran ejercer su actividad en el campo de las organizaciones sindicales, mutualidades, cooperativas, fundaciones, oficinas de colocación, universidades, etc. En el 19295, se produjo un cambio en el programa formativo, y éste pasa a estar constituido por tres cursos regulares y uno de especialización; superado este y presentada

2. Real Decreto de 14 de octubre de 1919, presentado por D. Luís Marichalar dentro de la Sección de Cultura Social del Instituto de Reformas Sociales.

3. El Real Decreto de la Presidencia de Gobierno de 17 de agosto de 1925, otorgó a la Sección de Cultura Social de Ministerio de Trabajo, Comercio e Industria, la condición de Escuela Social y fijó su ubicación en Madrid. El profesor fundador de la Escuela Social de Madrid fue Eugenio D’Ors, quien defendió la necesidad de añadir a las enseñanzas técnicas, económicas y jurídicas, las de carácter cultura y humano.

4. Los estudios estaban repartidos en tres años, en los que se impartían materias de política social, geografía humana, protección de los trabajadores, instituciones de previsión y seguros sociales, etc., así como una serie de enseñanzas prácticas, para finalizar con un trabajo monográfico de fin de carrera. En estos centros donde se formarían profesionales destinados a prestar servicios en el mundo del trabajo, y cuyo emblema era la Justicia Social.

5. Real Decreto 1988 de 7 de septiembre de 1929. 
una Memoria sobre un determinado tema designado por la Junta de profesores, se obtendría el Diploma de Graduado Superior. La orden ministerial de 17 de octubre de 1966, trajo consigo nuevos cambios en los planes de estudio, así como en la exigencia para poder acceder a las Escuelas Sociales de estar en posesión del título de Bachiller superior u otro título que habilitara para acceder a las Facultades Universitarias y Escuelas Técnicas de Grado Superior.

En el año 1980, la carrera de Graduado Social, se incorpora al mundo de la Universidad, por lo que los titulados tienen el reconocimiento de diplomados universitarios. Este último plan, previo a la reforma de 1990, abarcaba las áreas jurídica y económica, con una especial referencia al ámbito laboral. Tras la aprobación del Real Decreto 1429/1990, de 26 de octubre se estableció el título universitario de Diplomado en Relaciones Laborales, así como las directrices generales propias a las que debían sujetarse los planes de estudios consecuentes a la obtención de la mencionada titulación ${ }^{6}$ y el diseño de un perfil profesional excesivamente amplio para una Diplomatura, por lo que se hizo necesario la creación de un segundo ciclo, la Licenciatura en Ciencias del Trabajo.

Actualmente y tras el proceso de convergencia del Espacio Europeo de Educación Superior, aparece el Grado en Relaciones Laborales, fruto de la fusión entre la Diplomatura de Relaciones Laborales y la Licenciatura en Ciencias del Trabajo. Esta nueva titulación ha supuesto un profundo cambio metodológico, a la vez que organizativo y estructural.

El actual grado en Relaciones Laborales tiene una duración de cuatro años, y persigue entre otros los siguientes objetivos: que el alumnado adquiera los conocimientos necesarios para comprender el carácter dinámico y multidisciplinar del trabajo, desde su vertiente jurídica, organizativa, psicológica, sociológica, histórica y económica. Así como capacitarlos para la aplicación de los conocimientos teóricos y prácticos adquiridos, facilitándoles programas de prácticas y líneas de investigación que sirvan para una buena gestión del conocimiento en el ámbito de las relaciones laborales. Teniendo siempre presenta la aplicación de las TIC's, del aprendizaje autónomo y el trabajo en equipo.

Por tanto, los nuevos planes de estudios siguiendo las indicaciones del Libro Blanco, y tal como menciona el profesor A. Galán (2011) deben estar orientados a la consecución de los objetivos, tanto desde el punto de vista de los contenidos, como de las competencias y habilidades.

6. La carga lectiva global no podía ser inferior a 180 créditos. Repartidas entre 20 y 30 horas semanales, incluyendo el tiempo dedicado a las prácticas, y sin que la enseñanza teórica pueda superar las 15 horas semanales. Distribuidas en materias troncales, complementarias y formativas, así como prácticas integradas. 
La formación en competencias y el trabajo en equipo son las claves principales del nuevo modelo educativo plantado dentro del marco del Espacio Europeo de Educación Superior. Por tanto es necesario organizar los programas educativos, ajustando los contenidos y preparando actividades académicas dirigidas a esa finalidad.

Por otro lado, la creación del Espacio Europeo de Enseñanza Superior (EEES) ha generado un nuevo modelo educativo que basa su formación, precisamente, en el desarrollo de competencias, que tienen como objetivo fundamental la capacitación integral de las personas fomentado su permanencia en el mercado de trabajo a lo largo de toda la vida profesional.

De entre todas las competencias, este estudio se centra en el desarrollo del aprendizaje cooperativo, centrado principalmente en "cooperar para aprender" y "aprender más y mejor". Para ello se ha aplicado uno de las metodologías de educación universitaria, la mentorización, que está asumiendo un papel cada vez más relevante en los procesos de enseñanza-aprendizaje. Con la mentorización se crea un espacio de reflexión, encuentro y transferencia de conocimientos y experiencias, que pretende mejorar el aprendizaje y la adquisición de nuevas habilidades por parte de la persona mentorizada, a través del apoyo y la orientación del mentor. De entre todos los tipos de mentorización existentes hemos utilizado la mentorización grupal, formada por varios mentores y varios mentorizados.

Por otro lado, observamos que la web 2.0, muy extendida dentro del ámbito universitario, se ha convertido en una herramienta muy útil para organizar contenidos académicos, para realizar actividades de evaluación, así como para fomentar la posibilidad de compartir información en el desarrollo de las asignaturas. A pesar de ello, el potencial disponible en la actualidad en la red es más amplio y permitiría desarrollar otros tipos de actividades potencialmente útiles en el entorno educativo.

En este artículo aportamos la experiencia desarrollada en el Observatorio Local de Empleo de la Universidad de Huelva durante la estancia de investigación del alumnado del Máster en Políticas Territoriales de Empleo, en la que se ha utilizado Google Docs como herramienta de trabajo y de comunicación, lo que ha permitido que el alumnado realizara las actividades planteadas dentro del proceso de mentorización establecido con el objetivo de capacitar al alumnado en la competencia de trabajo colaborativa/cooperativo.

La experiencia ha resultado muy interesante, ya que ha permitido observar y valorar las ventajas e inconvenientes que supone la utilización de esta herramienta 2.0. A modo de evaluación, consideramos importante resaltar que se ha podido fomentar el trabajo en grupo, dada la interdependencia del alumnado para conseguir el objetivo planteado, a la vez que se ha promocionado la responsabilidad individual del alumnado, ya que el sistema requiere de la participación activa de todas las personas implicadas. 


\section{2.- EEES, APRENDIZAJE COOPERATIVO-COLABORATIVO}

El mercado de trabajo actual, requiere de profesionales con una multiplicidad de saberes, conocimientos y valores, además de formación técnica y científica. A ésto se les unen las exigencias de la sociedad del conocimiento, que implica un aprendizaje continuo, permanente y a lo largo de toda la vida. Así, cada vez es más necesario que el modelo de enseñanza universitaria se adapte a las exigencias de la sociedad.

Tras la creación del Espacio Europeo de Enseñanza Superior (EEES), se plantea la necesidad de adaptar los sistemas educativos universitarios a la sociedad del conocimiento, formado al alumnado de manera integral. De ahí que el sistema universitario comience a plantearse la formación basada en competencias.

Las competencias, conceptualizadas por una multitud de autores, se definen como el conjunto de conocimientos, capacidades, aptitudes, destrezas y habilidades necesarias para desempeñar una determinada función. Dentro del documento marco sobre la integración del sistema universitario español en el EEES se hace referencia a ellas de la manera siguiente: " los objetivos formativos de las enseñanzas oficiales de grados tendrán, con carácter general, una orientación profesional, es decir, deberán proporcionar una formación universitaria en la que se integren armónicamente las competencias genéricas básicas, competencias transversales relacionadas con la formación integral de las personas y las competencias más específicas que posibiliten una orientación profesional que permitan a los titulados una integración en el mercado de trabajo". (Ministerio de Educación, Cultura y Deporte, 2003).

Uno de los proyectos más importantes de la educación superior basada en competencias ha sido el denominado proyecto Tuning Educational Structures in Europe (Tuning - Universidad de Deusto, 2003), incluido dentro del EEES, que define las competencias desde la perspectiva de los resultados de aprendizaje como "el conjunto de conocimientos, comprensión y habilidades que se espera que el estudiante domine, comprenda y demuestre después de completar el proceso de aprendizaje". Las competencias se pueden dividir en dos tipos: competencias genéricas, que en principio son independientes del área de estudio y competencias específicas para cada área temática.

Las competencias se obtienen, normalmente, durante el desarrollo de diferentes unidades de estudio y por tanto pueden no estar ligadas a una sola unidad. Por lo que es muy importante identificar en qué unidades se enseñan las diversas competencias para asegurar una correcta evaluación efectiva y de calidad.

En este estudio nos hemos centrado en el desarrollo de la competencia aprendizaje cooperativo. Esta va a depender del intercambio de información entre los estudiantes, los cuales forman parte de un grupo, y se basa en la construcción colectiva del conocimiento y el desarrollo de habilidades de aprendizaje, y desarrollo 
personal y social, donde cada componente del grupo se responsabiliza tanto de lograr su propio aprendizaje como de acrecentar el nivel de logros de los demás miembros del grupo.

El objetivo del aprendizaje cooperativo es "cooperar para aprender" y "aprender más y mejor". Se coopera y se aprende si hay una tarea que realizar en grupo y supone necesariamente una mejora respecto a hacerla de forma individual, por lo que, cuando se plantean este tipo de tareas, debemos estar totalmente convencidos de la pertinencia de hacerla en grupo, así como de que el alumnado tome conciencia de las ventajas y ganancias que esto le va a reportar. En este caso, esto se concretó en la puesta en común de bibliografía, la preparación de documentos y material soporte, así como la elaboración y redacción del trabajo a desarrollar.

Por otro parte, podemos detallar algunas de las competencias que, según los autores Gil Montoya, C., Baños Navarro, R., Alias Saez, A. y Gil Montoya, D. (2007), se considera que se desarrollarían como consecuencia de la aplicación de este tipo de aprendizaje:

- Desarrollar la habilidad de trabajar en equipo, al motivar la participación activa de todo el alumnado.

- El pensamiento crítico y lógico al enfrentar al alumnado con determinadas situaciones.

- Búsqueda, selección, organización y valoración de la información.

- Capacidad de razonamiento.

- Aprendizaje autónomo.

- Habilidades de expresión oral y escrita.

- Responsabilidad.

- Planificación del tiempo.

En el marco del estudio realizado entre el alumnado del Máster Oficial de Políticas Territoriales de la Universidad de Huelva, durante el curso 2010-2011, el alumnado implicado desarrolló los siguientes aspectos:

Aprende de los ejemplos que proporcionan los demás, el otro funciona como referencia. El alumnado al estar realizando las tareas simultáneamente crea una situación en la que se ayudan unos a otros, lo que les permite, además, regular sus propias actuaciones tomando como modelo las de las compañeras.

Aparecen puntos de vista diferentes. El alumnado intercambia ideas, cada uno defiende su punto de vista, presenta argumentos, considera las razones o interpretaciones que aportan el resto de los miembros de grupo; llegando como resultado final a un acuerdo o punto en común. 
Habilidades comunicativas y sociales que siempre estarán presentes en este tipo de situaciones y que a su vez desarrollarán capacidades cognitivas relativas a la comprensión y expresión oral.

Distribución de tareas y responsabilidades. Si además éstas se van rotando, se facilita el que unos se pongan en el lugar de otros. Son situaciones que favorecen la toma de conciencia.

\section{3.- INVESTIGACIÓN EN RED}

Con la aparición de las tecnologías web 2.0 se produce una importante revolución en materia de creación y gestión de la información. Estos sistemas permiten crear nuevos espacios donde se puede, no sólo compartir conocimiento, sino que, a la vez, se puede generar nuevo. Pero su valor no radica en la posibilidad técnica de su existencia y de su manipulación, sino en las manifestaciones y fenómenos comunicativos a los que está dando lugar.

Según indica el autor O’Reilly, T. (2006), una de las grandezas que se atribuyen a Internet es que cualquier usuario, individual o colectivo, puede convertirse en emisor, creando y publicando su propio sitio web, ya que, gracias a las herramientas que facilita el entorno 2.0 es extremadamente fácil colocar contenidos en la red.

La Web 2.0 no sólo ofrece herramientas para trabajar en entornos contributivos sino que, además, otorga a la comunidad la posibilidad de ejercer su "inteligencia colectiva", entendida como la capacidad del grupo para resolver problemas que cada individuo del colectivo, de forma personal, no sería capaz de resolver ni, incluso, de entender (Ribes, X., 2009). La inteligencia colectiva provocará, por ejemplo, que cierta referencia aparezca mejor o peor situada en Google, considerada ésta como la señal de identidad de la web 2.0.

No nos vamos a referir a web 2.0 sólo como una tecnología, sino como un nuevo modelo que dispone de una serie de herramientas capaces de generar, obtener, tratar, compartir y distribuir información, que pueden ser aplicadas por los investigadores, tanto para realizar trabajos de forma cooperativa como para intercambiar recursos de manera colaborativa o difundir resultados en sistemas participativos.

La web 2.0, también denominada web participativa, se caracteriza por el empleo de tecnologías abiertas y por la introducción de cambios significativos en el ámbito científico. Las formas como se emplea en la investigación, y sobre todo en la información bibliográfica y en la relación entre investigadores son las siguientes:

- compartir la investigación

- compartir los recursos

- compartir los resultados 
Para que los investigadores puedan compartir sus actividades, la web 2.0 dispone de plataformas específicas destinadas a intercambiar información, recursos y documentos. No se trata simplemente de herramientas a través de las cuales se puede conocer el perfil de un investigador y leer sus trabajos, sino son lugares de ciencia abierta donde se comparte de forma efectiva currículos, investigaciones, hipótesis, etc. Entre esas herramientas destacamos las siguientes:

Las redes sociales científicas. Actúan de la misma forma que una red social de ámbito general, en la que las personas o entidades pueden comunicarse de forma rápida y simultánea, así como compartir recursos de información y documentación de todo tipo. Las redes sociales científicas son excelentes laboratorios virtuales, ya que ofrecen todos los servicios que un grupo de investigación necesita, foros, medios para compartir recursos, archivo de documentos, etc.

Las bases de datos de científicos. Permiten que investigadores con perfiles similares se relacionen. Se trata de plataformas planteadas como directorios de especialistas que ponen en común sus datos, sus áreas de investigación y su producción científica.

Las plataformas para la investigación. En ellas se establece una colaboración real entre los investigadores, lo que permite a un investigador dar a conocer sus resultados y poder intercambiar opiniones con el resto. Son el mejor ejemplo de cómo las tecnologías participativas están ayudando a la ciencia en todos los procesos de investigación, ya que permiten una pluralidad de servicios que van desde la creación de redes temáticas específicas, hasta la posibilidad de compartir datos o la creación de depósitos compartidos de documentos.

Las herramientas colaborativas o también denominados servicios instrumentales participativos. Son muy útiles para los investigadores ya que les permiten disponer de servidores en los que depositar sus documentos, archivos y demás datos que quieren compartir con su equipo, para que sean revisados, editados o modificados. Se trata de plataformas que garantizan que todo un equipo de investigación está trabajando con la versión correcta de un archivo y que permiten comprobar las modificaciones y aportaciones que se han ido realizando.

Los investigadores necesitan emplear recursos de información para su trabajo, los cuales pueden ser de utilidad para los miembros de su equipo, por lo que es necesario compartir todos y cada uno de los recursos utilizados. De entre las herramientas que pone a disposición de la web 2.0, nos encontramos con los gestores de referencias bibliográficas y los favoritos sociales. Los primeros son aplicaciones destinadas a manejar bases de datos de referencias bibliográficas obtenidas a partir de distintas fuentes, capaces de crear, mantener, organizar y dar forma a toda la bibliografía usada, de acuerdo con diferentes estilos de citación. Los diferentes gestores comparten las mismas funciones básicas de almacenamiento, descripción, organización, recuperación, creación y herramientas de citación. 
La web 2.0 permite publicar información que se puede compartir, por lo que es de gran utilidad dentro de la comunidad científica a la hora de transmitir los resultados obtenidos de sus investigaciones. Entre las herramientas que se utilizan, destacan los blogs y las wikis científicas, así como los servicios de noticias científicas y las plataformas de acceso abierto. Los blogs y las wikis son una excelente herramienta de difusión de resultados para los investigadores, quienes ven en estos sitios el lugar sencillo y rápido de compartir información y generar discusión.

En esta experiencia nos hemos centrado en los servicios instrumentales participativos, concretamente en la herramienta Google Docs, que permite crear documentos, hojas de cálculos y presentaciones, además de servicios complementarios como compartir calendarios, establecer citas, reuniones, planes de trabajo, etc.

\section{4.- NUEVAS METODOLOGÍAS DOCENTES: LA MENTORIZACIÓN}

El EEES apuesta por el asesoramiento y la orientación, lo que implica un cambio importante en el enfoque de los métodos docentes. Dentro de esos métodos, vamos a centrarnos en la mentorización, que está asumiendo un papel relevante en los procesos de enseñanza-aprendizaje.

Históricamente el término "mentorización" tiene su origen en la obra de Homero "La Odisea". Mentor fue el guía y el asesor de Telémaco, hijo de Ulises, cuando aquel tiene que hacerse cargo de todas las tareas y responsabilidades de su familia ante la ausencia de su padre. Posteriormente, en el siglo XVIII, el escritor francés Fénelon hace referencia a su Mentor como su guía y educador, por lo que desde ese momento, la mentorización siempre ha estado relacionada con la educación. Sin embargo, con el paso del tiempo, el término ha ido ampliando su campo de acción, por lo que actualmente se le relaciona con el arte de dar consejos, ayudar y/o asesorar.

Hoy en día nos encontramos con muchas definiciones del término, vamos a centrarnos en la aportada por Penny (2008), quien señala a la mentorización como aquel proceso que tiene el objetivo de mejorar el aprendizaje, la adquisición de nuevas experiencias y nuevas habilidades de una persona, el mentorizado, a través del apoyo y la orientación de otra, el mentor. Se establece entre ellos una relación basada en la reflexión y la transferencia de conocimientos y experiencias. A la vez que, proporciona la posibilidad de compartir estrategias, analizar, confrontar y reflexionar sobre la práctica profesional e introduce mejoras de manera guiada y con apoyo. Es importante destacar que no sólo favorece el aprendizaje del mentorizado, sino que produce mejoras en el mentor, como consecuencia de que éste se ve inmerso en espacios de reflexión sobre su propia actuación, favoreciendo con ello su mejora profesional.

De la definición aportada por los autores Pinto Molina, M. y Uribe Tirado, A. (2010), se desprende que la mentorización consiste en desarrollar y crear relaciones 
donde una persona invierte su tiempo, su saber-como (know how) y hace un esfuerzo con la finalidad de potenciar el desarrollo de otra persona, en el ámbito de los conocimientos y las habilidades.

La mentorización trata de innovar en múltiples aspectos como medio para conseguir un mayor nivel de calidad en la docencia e investigación dentro de las universidades.

Como hemos señalado anteriormente, en la mentorización existen dos figuras claves, el Mentor y el Mentorizado. El Mentor es aquella persona que tiene interés y voluntad por ayudar, guiar, apoyar y asesorar a otra; siendo la pieza principal en el modelo de enseñanza-aprendizaje, ya que es el transmisor de competencias. El Mentorizado, por su parte será alguien que pide y acepta ayuda, orientación, apoyo y asesoramiento de otro.

De forma general podemos diferenciar dos tipos de mentorización: la informal o natural que aparece de forma espontánea entre dos personas que tienen un mismo interés y donde la más experimentada aconseja e informa a la otra, que está centrada en la buena actitud y disponibilidad; y la formal u organizada, que conlleva el aprendizaje y la gestión de conocimiento, en la que son formados tanto el mentor como el tutelado y donde una tercera parte se encarga de relacionarlos. Desde otra perspectiva, los procesos de mentorización se pueden clasificar en los siguientes tipos o modelos:

- Mentorización individual, en la que participan un mentor y un pupilo.

- Mentorización en grupo, en la que intervienen un mentor y varios mentorizados.

- Mentorización entre iguales, en caso de que el mentor no esté más experimentado que el mentorizado, sino que ambos comparten sus experiencias.

- e-mentoring, que se realiza a distancia.

- Mentorización grupal, en la que participan varios mentores y varios mentorizados en un único proceso de mentorización.

La experiencia que se expone en el presente artículo se basa en un proceso de mentorización de carácter grupal.

\section{5.- HERRAMIENTAS 2.0: GOOGLE DOCS}

Google Docs es la aplicación de Google para crear y compartir documentos de trabajo online. Nace a partir de dos productos separados, Writely y Google Spreadsheets. Writely era un procesador de texto individual en red creado por la compañía de software Upstartle, el cual fue lanzado en agosto de 2005. Sus características originales incluían un sitio para la edición de textos en colaboración, además de controles para 
su acceso. Los menús, atajos en el teclado y cuadros de diálogo eran presentados de una manera muy similar a la que los usuarios suelen esperar en un procesador de texto tradicional, como OpenOffice o Microsoft Office.

Google desarrolló Google Spreadsheets introduciendo muchas de las bondades encontradas hoy en Google Docs. Google anunció Spreadsheets el 6 de junio de 2006 e inicialmente sólo lo puso a disposición de una cantidad muy limitada de usuarios, según orden de llegada. Posteriormente en febrero de 2007 Google Docs fue de libre acceso para todos los usuarios y en Septiembre de ese mismo año lanzó un programa de presentación de documentos, sin embargo no ha sido hasta enero de 2010 cuando ha empezado a aceptar cualquier tipo de archivo.

Esta herramienta es un conjunto de aplicaciones en línea que incluyen procesador de texto, hoja de cálculo, una aplicación para presentaciones, así como un repositorio para archivos de imágenes y pdf., que permite crear, editar y compartir documentos en la web entre varios usuarios, los cuales pueden tener distintos perfiles de acceso y uso. Siendo accesible, por tanto, desde cualquier ordenador y sistema operativo, y permitiendo la importación y exportación de documentos. Entre sus principales características podemos citar la admisión de establecer formularios para recolectar datos e incorporarlos en hojas de cálculo, editar documentos, crear carpetas personales, integrar diccionarios en línea, así como herramientas de traducción y revisión ortográficas; todo ello de una forma rápida y efectiva.

La gran utilidad de Google Docs es poder subir a la red documentos que queramos compartir y editar con otras personas. Su repositorio y editores nos liberan de todas las limitaciones que puedan tener el software de tipo comercial.

Imagen 1: ¿Qué es Google Docs?

¿Qué es Google Docs?

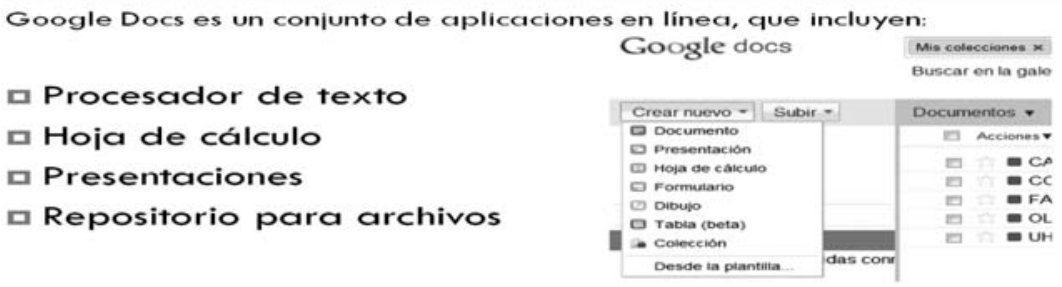

Fuente: Elaboración propia a partir de imágenes de Google Docs. 
En cuanto al uso, las barras de herramientas de las distintas aplicaciones on-line para documentos y hojas de cálculo son las mismas que las que podemos encontrar en cualquier paquete de ofimática, sin mayor dificultad. Una vez subido o modificado el documento siempre podemos elegir entre opciones como publicar y compartir, dependiendo si lo queremos incrustar en algún sitio web propio o si deseamos iniciar una tarea colaborativa con otros miembros a quienes podemos invitar con privilegios o no de edición.

IMAGEN 2: Gestión DE USUARIOS/AS.

\section{Usuarios/as y visibilidad}

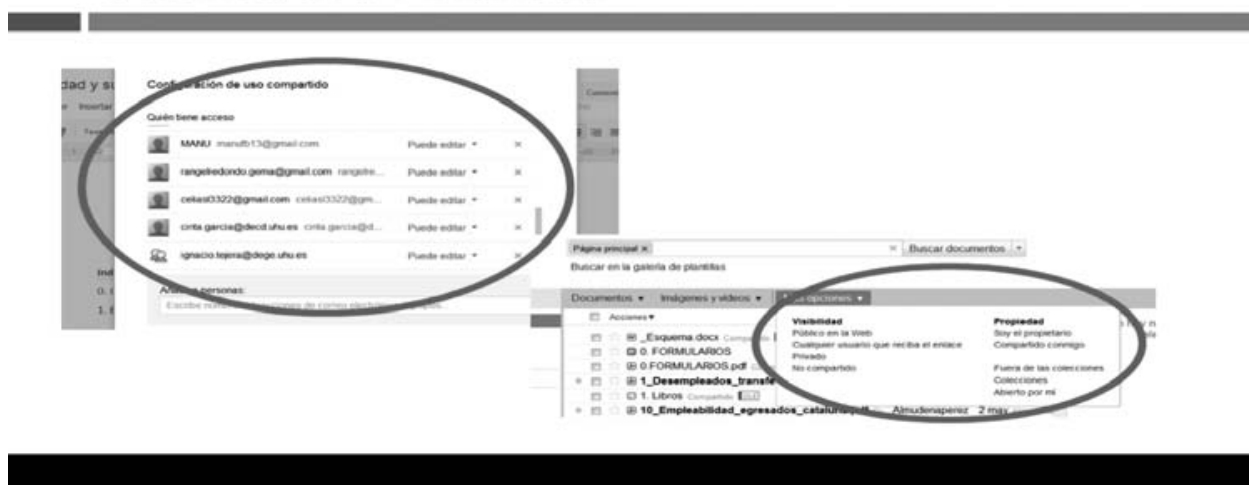

Fuente: Elaboración propia a partir de imágenes de Google Docs.

Centrándonos en su aplicación al entorno educativo, señalar que, tal como indica Gómez M., Google Docs facilita dos de las herramientas más utilizadas en educación (los procesadores de texto y los programas de presentación). La posibilidad de almacenar los documentos en la red y de trabajar con ellos varias personas, permite la elaboración conjunta de trabajos (textos escritos) mediante la escritura colaborativa, lo que permite la implicación del alumnado en una tarea común que integra lectura y escritura.

Todos los trabajos y documentos creados por el alumnado pueden ser preparados en el aula o de forma individual en otro entorno, de modo que permite un trabajo continuado y coordinado. El hecho de que los citados documentos puedan ser publicados y compartidos por todos los miembros del grupo, hace que el aprendizaje sea recíproco. A la vez, se potencia el trabajo colaborativo y la actitud de ayuda y 
cooperación, desarrollando con ello las habilidades necesarias para que el grupo funcione de forma efectiva, como el trabajo en equipo, el liderazgo y la solución de conflictos. De esta forma cada uno de los miembros del grupo de trabajo es responsable de su desempeño individual dentro del grupo, lo que reporta un enriquecimiento personal mediante el conocimiento de experiencias ajenas. Valores como el respeto a opiniones diferentes, la aceptación de las críticas o la responsabilidad y regulación del tiempo de trabajo, pueden ser consecuencias del buen aprovechamiento de este recurso educativo.

Las posibilidades que ofrece Google Docs en el ámbito educativo son infinitas, por lo que podría ser aplicado en cualquier especialidad docente, donde la base sea desarrollar trabajos, fomentar el debate e iniciar procesos de investigación.

En nuestro caso, la finalidad que se ha pretendido alcanzar es la de realizar un trabajo de iniciación a la investigación, utilizando el aprendizaje colaborativo y con ello desarrollar en el alumnado las siguientes competencias:

- Realizar trabajos colaborativos utilizando herramientas 2.0.

- Enriquecimiento personal mediante el conocimiento de las experiencias ajenas.

- Actitud de ayuda y cooperación.

- Respeto a las opiniones diferentes y la aceptación de las críticas.

- Responsabilidad y regulación del tiempo de trabajo.

\section{6.- DESCRIPCIÓN DE LA EXPERIENCIA}

El proceso de mentorización que exponemos se ha llevado a cabo en el marco del módulo de investigación del Máster Oficial de Políticas Territoriales de Empleo, impartido por la Universidad de Huelva. El citado módulo ofrece la posibilidad de hacer prácticas o estancias de investigación en un organismo o departamento de la universidad. En este caso, la estancia de investigación se ha desarrollado en el Observatorio Local de Empleo de la Universidad de Huelva, centro de investigación creado como instrumento para la observación estratégica y la evaluación participativa al servicio de lo local, y para el desarrollo de acciones y estrategias que favorezcan el empleo.

La mentorización, con una duración de dos meses, se planteó con el objeto de facilitar un primer acercamiento del alumnado a los procesos de investigación, de forma que, tras finalizar el proceso, el alumnado fuera capaz de realizar pequeños trabajos de investigación con éxito. El énfasis del proceso se ha centrado, dado el carácter pedagógico de la experiencia, en la asimilación de la metodología de investigación que en los resultados de la investigación planteada. 
Si bien la mayor parte de los procesos de mentorización tienen carácter individual, en esta experiencia se ha aplicado la mentorización grupal, formada por varios mentores y varios mentorizados, en la que han participado cuatro profesores y cuatro alumnas, junto a la directora del Observatorio Local de Empleo.

El perfil del alumnado ha sido bastante uniforme, ya que se trata de alumnas recién licenciadas sin experiencia profesional, mientras que los perfiles del profesorado son más dispares, dado que hay profesoras (doctoras) con mucha experiencia en docencia e investigación, y profesores con experiencia en docencia relacionada con el tema de la investigación, pero con menos experiencia investigadora.

El contenido de la investigación que se plantea desde la dirección del Observatorio Local de Empleo es realizar un análisis en profundidad del concepto "empleabilidad" tanto desde una perspectiva histórica como conceptual, dado que el alumnado conoce este término, en el marco del estudio del mercado de trabajo y las políticas de empleo, pero desde una visión muy pragmática del mismo.

El desarrollo de la investigación se plantea siguiendo una metodología semipresencial, de forma que el grupo de alumnas trabajará de forma no presencial, con una reunión semanal de seguimiento. En este contexto, se plantea la necesidad de establecer un sistema de trabajo que permitiera, además de alcanzar los objetivos de la estancia de investigación, gestionar y canalizar la complejidad del trabajo del grupo, por lo que se hacía necesario que dicho sistema tuviera la posibilidad de poder:

- Ser accesible desde cualquier puesto informático en cualquier ubicación.

- Ser utilizado sin adiestramiento previo, dada la limitación de tiempo para alcanzar los resultados.

- Compartir información entre el alumnado, de forma que pudieran trabajar simultáneamente sobre un mismo documento y compartiendo las fuentes.

- Compartir información con el profesorado, de forma que se pudiera realizar un seguimiento continuo de los progresos alcanzados por el alumnado.

- Crear nuevo conocimiento. La herramienta a utilizar debía facilitar la creación de nuevo conocimiento colaborativo.

- Poder avanzar en el desarrollo del documento en tiempo real, evitando que circulen múltiples versiones del documento.

- Además, dada la metodología que se plantea para el desarrollo de la investigación, se hace necesario tomar en consideración las siguientes variables:

- Participación activa de todos los miembros del grupo.

- Limitación en la disponibilidad de tiempo.

- Trabajo en red del alumnado y el profesorado. 
- Comunicación constante entre el alumnado y con el profesorado.

- El sistema debe permitir la evaluación individual y grupal.

En este contexto, y en base a las necesidades planteadas y las variables a considerar, se hacía necesario plantear un sistema de trabajo y comunicación en red se vislumbra como un elemento clave para garantizar el correcto desarrollo del mismo. Así, en la reunión de acogida se plantea la utilización de herramientas web 2.0 para facilitar este objetivo, en concreto se propone el uso de "Google Docs" como sistema de trabajo.

Google Docs es un conjunto de aplicaciones en línea que incluyen procesador de texto, hoja de cálculo, una aplicación para presentaciones, así como un repositorio para archivos de imágenes y pdf. Permite crear, editar y compartir documentos en la web entre varios usuarios que, además, pueden tener distinto perfiles de acceso y uso. Google Docs es accesible, por tanto, desde cualquier ordenador y sistema operativo y permite la importación y exportación de documentos.

La razón de seleccionar Google Docs como herramienta de trabajo se ha basado en su sencillez de uso, muy similar a los paquetes de ofimática a los que estamos acostumbrados, la inmediatez de su utilización, ya que no requiere de ningún tipo de alta o configuración previa, así como el hecho de poder trabajar en tiempo real y poder realizar el seguimiento de las aportaciones y modificaciones de cada miembro del equipo de trabajo. A lo que se le une otros factores, tales como la gratuidad de su utilización, la capacidad para reducir distancias (teoría de los seis grados de separación), el permitir modificar códigos y roles (diluyen jerarquías), así como el permitir la realización de trabajos colaborativos y el desarrollo de múltiples competencias.

\section{7.- CONCLUSIONES}

La experiencia con Google Docs ha resultado muy interesante y útil, ya que ha permitido observar y valorar las ventajas e inconvenientes que supone la utilización de esta herramienta 2.0.

Como primera conclusión, y desde la perspectiva de la mentorización, esta herramienta ha permitido mantener un contacto directo y continuo entre todas las personas participantes en el desarrollo de la actividad planteada, fomentando no sólo la transmisión y creación de conocimientos, sino también la optimización de los tiempos y la orientación y redirección continua de la actividad.

Respecto a la dinámica de trabajo en grupo, es importante resaltar que esta herramienta permite, a la vez, fomentar el trabajo en grupo y el trabajo individual, en tanto que promueve la interdependencia entre alumnado para conseguir el objetivo a alcanzar, a la vez que requiere de la responsabilidad individual de cada persona participante para que el grupo avance. 
Durante el desarrollo de la actividad quedó claramente patente la sencillez de uso ya que, tanto el alumnado como el profesorado, utilizó la herramienta desde el primer momento sin que supusiera retraso alguno, más bien al contrario en tanto que permitió compartir el desarrollo del trabajo desde el inicio. Así, se diseño una tabla vinculada a un formulario para que el alumnado registrara las referencias bibliográficas y subiera los archivos (artículos, estudios ...) , por lo que se aglutinó toda la información bibliográfica en una única fuente lo que permitió acelerar sobremanera el proceso de búsqueda bibliográfica evitando duplicidades.

Imagen 3: Detalle de archivos diseñados

\begin{tabular}{|c|c|c|c|}
\hline \multirow{2}{*}{\multicolumn{2}{|c|}{$\begin{array}{l}\text { Documentos } \mathbf{\nabla} \text { Imágenes y videos } \boldsymbol{\nabla} \text { Más opciones } \mathbf{\nabla} \\
\square \text { Acciones } \mathbf{V}\end{array}$}} & \multirow[b]{2}{*}{ Ordenar por Titulo $\mathbf{V}$} & \multirow[b]{2}{*}{ Ver Detalles $\mathbf{v}$} \\
\hline & & & \\
\hline 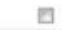 & (18 0.FORMULARIOS.pdf Compartido & yo & $8 \mathrm{abr}$ yo \\
\hline$\square$ & 曰1. Libros Compartido & yo & $9 \mathrm{abr}$ yo \\
\hline घ & 2. Capitulos Compartido & yo & 15 abr Sandra qu \\
\hline ש & 3. Revistas Compartido & yo & 28 abr Almudent \\
\hline$\Delta$ & 4. Documentos electrónicos Compartido & yo & 31 may Ramiro: \\
\hline$\nabla$ & 6. Congresos Compartido & yo & 28 abr Almudent \\
\hline घ & - Carpeta de documentos (subir pdf) Compartido & yo & 3 may Ramiro es \\
\hline$\square$ & Documentos de trabajo Compartido & yo & 21 abr Sandra qu \\
\hline
\end{tabular}

Fuente: Elaboración propia a partir de imágenes de Google Docs.

Desde este momento fue evidente la necesidad de que todo el alumnado participara de forma activa asumiendo responsabilidades individuales para poder garantizar el desarrollo equilibrado del estudio. Esta interdependencia entre todas las personas participantes no sólo no ha dificultado el proceso sino que ha supuesto un factor de motivación para la participación en el grupo.

Imagen 4: Detalle del documentado redactado por los usuarios (Colores)

\section{Documentos}

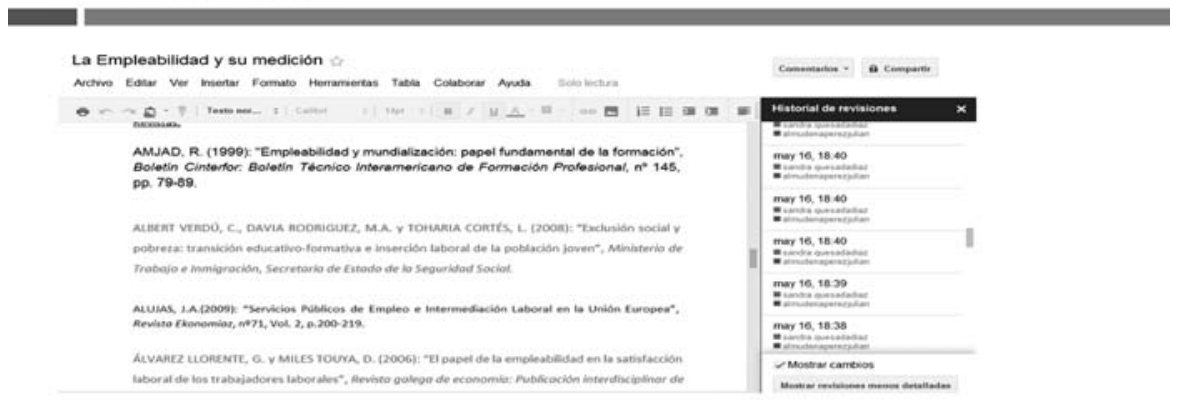

Fuente: Elaboración propia a partir de imágenes de Google Docs. 
Este proceso participativo llevado a cabo ha permitido, por tanto, mejorar el nivel de calidad del mismo, en tanto que ha permitido acceder a más bibliografía y más puntos de vista. Es cierto, sin embargo, que el proceso de desarrollo de la actividad ha sido más lento en tanto que ha requerido cierto nivel de ajuste en los tiempos individuales para adaptarse el desarrollo del trabajo del grupo. Además, este sistema permite establecer un único canal de comunicación y trabajo del grupo evitando el uso de otras herramientas informáticas externas al mismo (repositorios, correo electrónico ...).

En términos de evaluación, para el profesorado ha sido una experiencia de gran interés, no sólo por la posibilidad de experimentar nuevos sistemas de trabajo, sino porque, además, esta herramienta ha permitido llevar el seguimiento individualizado de cada persona, constatándose que no todos los miembros del grupo se han implicado de la misma manera, si bien todos los hecho de forma razonablemente adecuada para el objetivo marcado.

Sin duda, Google Docs puede asumir un papel de gran relevancia como herramienta de apoyo a procesos de generación de conocimiento colectivo en el ámbito universitario y de otros niveles educativos, y en cualquier disciplina. Consideramos que es especialmente recomendable como apoyo para procesos de enseñanza-aprendizaje poco estructurados y con grupos de estudiantes reducidos, como ha sido el caso expuesto en el presente documento.

En definitiva, se ha constatado que Google Docs va más allá de la gestión de información y la comunicación, más allá de mostrar la información, y se convierte en un auténtico sistema de trabajo que permite crear nuevo conocimiento colectivo, lo cual le confiere un papel relevante como medio para gestionar grupos de trabajo en el ámbito educativo.

\section{8.- BIBLIOGRAFÍA}

BEY, T.M. y HOLMES, C.T. (1992): Mentoring: Contemporary Principles and Issues, Boston, Association of Teachers Educators, 1992. En PINTO MOLINA, M. y URIBE TIRADO, A. (2010): "Formarnos y Autoformarnos en alfabetización informacional. Un programa de mentorización en bibliotecas universitarias-CRAI".

CELAYA, J. O: "Impacto de las Tecnologías Web 2.0 en la comunicación cultural". Inclusiva-net. URL: www.medialab-prado.es. Consultado 21/Noviembre 2011

CLARES, B. y otros (2010): Mentoria intergradual en un equipo de investigación. Comunicación II Congreso Internacional de Didáctica 2010. URL: http://www. udg.edu/portals/3/didactiques2010/guiacdII/ACABADES\%20FINALS/257.pdf. Consultado 04/Julio 2011 
CLUTTERBUCK, D. (2001): Everyone needs a mentor: Fostering talent at work. CIPD:London.

GALAN GARCIA, A. HERRAIZ MARTIN, Ma S. (2005): "La Enseñanza en las Relaciones Laborales en España”. Revista Trabajo no: 15 (revista de la asociación estatal de centros universitarios de relaciones laborales y ciencias del trabajo). Enero-Junio 2005. Servicio de publicaciones de la Universidad de Huelva. ISSN: 1136-3819. Depósito Legal: SE-724-96.

GALAN GARCIA, A. (2011): "El Proceso de Convergencia desde el Grado de Relaciones Laborales y Recursos Humanos: una ojeada al panorama nacional”. Capítulo Reflexiones generales en el Libro: EEES y Cambios en las Metodologías Docentes: Reflexiones y Experiencias en su aplicación a las Ciencias del Trabajo. Coord. Por Maria del Milagro Martín López, Adela Roldán Márquez. Editores: Tirant lo Blanch, Valencia 2011. ISBN: 978-84-9985-068-9. Pág. 15-45.

GARCIA FERNANDEZ, P., y otros (2009): "Primera experiencia de mentorización multidisciplinar de profesores principiantes en la Facultad de Ciencias de la Universidad de Granada". Actas Primeras Jornadas de Intercambio de Experiencias de Mentorización en la Educación Superior, 2009. ISBN 978-84-692-6405-8, págs. 22-32.

GIL MONTOYA, C., BAÑOS NAVARRO, R., ALIAS SAEZ, A. Y GIL MONTOYA, D. (2007): "Aprendizaje Cooperativo y desarrollo de competencias". URL: http:// www.greidi.uva.es/JAC07/ficheros/30.pdf. Consultado 01/Septiembre 2011.

GOMEZ, M. O: "De Aplicaciones educativas de las herramientas de Google". URL: https://sites.google.com/site/rmipasico/google-docs-en-el-aula. Consultado 21/ Noviembre 2011

GUTIERREZ DEL MORA, Mª J (2009): "El Trabajo cooperativo, su diseño y su evaluación. Dificultades y propuestas. Actas del congreso Univest09. Gerona noviembre 2009. URL: http://dugi-doc.udg.edu/bitstream/10256/1956/1/217.pdf. Consultado $\underline{01 / \text { Septiembre } 2011 .}$

MARCELO, C. (1994). Formación del profesorado para el cambio educativo. Barcelona: PPU. En CLARES, B. y otros (2010): "Mentoria intergradual en un equipo de investigación”.

MILLER, ANDREW (2002): "Mentoring students and young people: a handbook of effective practice". Kogan Page: Londres.

MINISTERIO DE EDUCACIÓN, CULTURA Y DEPORTE (2003): La integración del sistema universitario español en el Espacio Europeo de la Educación Superior. Documento Marco. Madrid. 
OlMO, J. C.; DELGADO, Á.; PASADAS, M.; JADRAQUE, E.; y DELGADO, E. (2010): "De la mentorización individual a la formación de un grupo docente". En: Actas de las I Jornadas sobre Innovación Docente y adaptación al EEES en las Titulaciones Técnicas. Granada: Universidad de Granada.

O’REILLY, T. (2006): "Qué es Web 2.0. Patrones del diseño y modelos del negocio para la siguiente generación del software”. URL: http://sociedadinformacion.fundacion.telefonica.com/DYC/SHI/seccion=1188\&idioma=es ES\&id=2009100116300061\&activo=4. do?elem=2146. Consultado 21/Noviembre 2011

ORTEGA, M., MELERO, M. (1999): "El aprendizaje cooperativo". Fondo de publicaciones del Gobierno de Navarra. Gráficas Lizarra. Pamplona. ISBN: 84-235-1934-1. URL: http://sauce.pntic.mec.es/falcon/aprencooper.pdf. Consultado 10/Septiembre 2011

PINTO MOLINA, M. y URIBE TIRADO, A. (2010): "Formarnos y autroformarnos en alfabetización informacional. Un programa de mentorización en bibliotecas universitarias-CRAI". Investigación Bibliotecológica, Vol. 24, Núm. 52, septiembre/ diciembre, 2010, México, ISSN: 0187-358X. pp. 63-95.

PLATAFORMA DE TRABAJADORES DE COLEGIOS PROFESIONALES (2009): "Manifiesto en Defensa de los Colegios Profesionales". URL: http://www.copitiva.es/ phpbb/viewtopic.php?f=3\&t=2. Consultado el día 14/08/2010.

REBIUN (2010): Ciencia 2.0: Servicios de la Web Social para la investigación.

RIBES, X. (2009): "La Web 2.0. El valor de los metadatos y de la inteligencia colectiva". Revista Telos. URL: http://sociedadinformacion.fundacion.telefonica.com/telos/articuloperspectiva.asp@idarticulo=2\&rev=73.htm. Consultado 21/Noviembre 2011.

UNION PROFESIONAL (2009): "Jornada: El impacto de la reforma de los colegios Profesionales". Nota de Prensa. Madrid 17 de Septiembre 2009. URL: http:// www.unionprofesional.es

UNION PROFESIONAL (2009): "La reforma de los colegios profesionales". URL: http:// www.unionprofesional.es

UNIVERSIDAD DE DEUSTO (2003): Tuning Educational Structures in Europe. Informe Final Fase Uno. Editado por Julia González y Robert Wagenaar. ISBN: 84-7485892-5. URL: http://www.relint.deusto.es/TUNINGProject/spanish/doc_fase1/ Tuning\%20Educational.pdf. Consultado 10/Septiembre 2011

VIZCARRO, C. (2007): Introducción a la Docencia Universitaria. Algunas estrategias docentes: UCLM - UICE.

ZABALA, M.A. (2002). La enseñanza universitaria. El escenario y sus protagonistas. Madrid: Narcea. 
